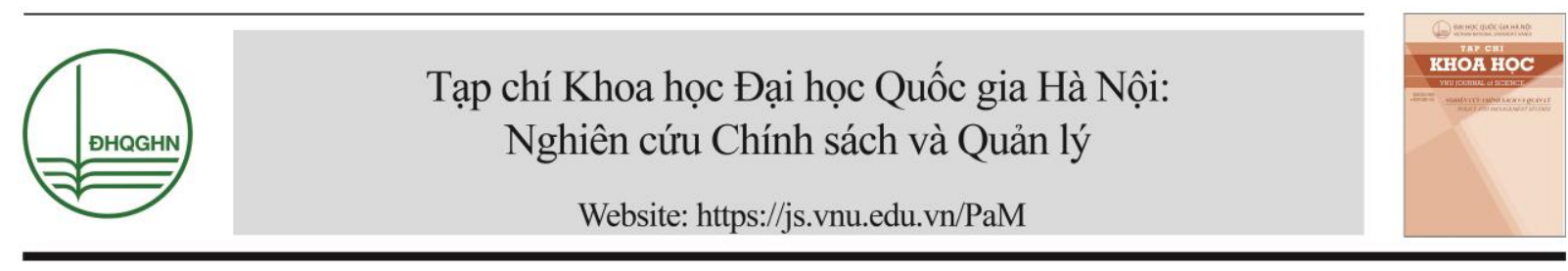

\title{
Nâng cao năng lực đổi mới trong doanh nghiệp kinh nghiệm của Hàn Quốc, Malaysia và đề xuất với Việt Nam
}

\author{
Vũ Văn Khiêm, Hồ Thế Nam Phương, Bùi Tiến Dũng \\ ${ }^{1}$ Truờng Đại học Văn Lang, 45 Nguyễn Khắc Nhu, Cô Giang, Quận 1, Thành phố Hồ Chí Minh \\ ${ }^{2}$ Truòng Đại học Khoa họ Xã hội và Nhân Văn, ĐHQGHN, \\ 336 Nguyễn Trãi, Thanh Xuân, Hà Nội, Việt Nam \\ ${ }^{3}$ Học viện Khoa học Công nghệ và Đổi mói sáng tạo, Bộ KH\&CN, 38 Ngô Quyền, Hoàn Kiếm, Hà Nội \\ Nhận ngày 16 tháng 1 năm 2018 \\ Chỉnh sửa ngày 20 tháng 2 năm 2018; Chấp nhận đăng ngày 28 tháng 3 năm 2018
}

\begin{abstract}
Tóm tắt: Bài viết này nghiên cứu chính sách nâng cao năng lực đổi mới (innovation) trong doanh nghiệp với kinh nghiệm Hàn Quốc, Malaysia. Đây là hai quốc gia tiêu biểu về thực hiện chính sách nâng cao năng lực đổi mới trong doanh nghiệp thành công. Các quốc gia này có xuất phát điểm với điều kiện, hoàn cảnh khác nhau, nhưng họ thực hiện các chính sách nâng cao năng lực đổi mới trong doanh nghiệp phù hợp đã giúp họ nhanh chóng trở thành các quốc gia có vị thế cao trên thế giới. Hàn Quốc, Malaysia trước đây có nhiều điểm tương đồng với Việt Nam hiện nay gợi suy cho nước ta trong hoạch định chính sách nâng cao năng lực đổi mới của các doanh nghiệp.
\end{abstract}

Tù khóa: Chính sách, năng lực đổi mới, doanh nghiệp.

\section{Giới thiệu}

Trong Báo cáo về mức độ sẵn sàng cho tương lại các nền sản xuất năm 2018 tại Diễn đàn kinh tế thế giới [1], Việt Nam xếp thứ hạng 48/100 quốc gia về cấu trúc của nền sản xuất và thứ hạng 53/100 quốc gia về các yếu tố dẫn dắt sản xuất. Trong Báo cáo phân loại thành bốn nhóm các quốc gia bao gồm nhóm dẫn đầu, nhóm tiềm năng cao, nhóm di sản và nhóm sơ khai, Việt Nam được xếp vào nhóm "Sơ khai"

\footnotetext{
*Tác giả liên hệ. ĐT.: 84-.

Email:

https://doi.org/10.25073/2588-1116/vnupam.4144
}

bởi nước ta là những quốc gia có cấu trúc sản xuất đơn giản và các yếu tố dẫn dắt sản xuất không thuận lợi. Tuy Việt Nam nằm ở nhóm "Sơ khai" nhưng lại gần sát nhóm tiềm năng cao. Việc có cấu trúc sản xuất đơn giản nhưng Các yếu tố dẫn dắt sản xuất gần nhóm tiềm năng cao (đứng thứ 53 trong 100 quốc gia) có nghĩa là Việt Nam có thể được hưởng lợi từ việc đi sau, không bị trói buộc quá lớn vào hệ thống sản xuất hiện có bởi do ta có cấu trúc sản xuất đơn giản (xem Bảng 1 dưới đây).

Bảng 1 cho thấy hai yếu tố thấp nhất là công nghệ và đổi mới với 3,1 điểm, xếp hạng 90/100. 
Bảng 1. Điểm số và thứ hạng các yếu tố cơ bản của Việt Nam

\begin{tabular}{lll}
\hline Chỉ số & Điểm số & Xếp hạng \\
\hline Cấu trúc & & \\
1. Tính phức tạp (điểm 1-10) & 4,4 & 72 \\
2. Quy mô (điềm 1-10) & 5,8 & 17 \\
Yếu tố dẫn dắt & 4,5 & 70 \\
1. Vốn con người (điểm 0-10) & 7,0 & 13 \\
2. Thương maí toàn cầu và Đầu tư (điểm 0-10) & 5,0 & 53 \\
3. Khuôn khồ thề chê̂ (điểm 0-10) & 4,6 & 87 \\
4. Nguồn lực bền vững (điểm 0-10) & 5,2 & 39 \\
5. Môi trường nhu cầu (điềm 0-10) & 3,1 & 90 \\
6. Công nghệ và đổi mới(điểm 0-10) & \\
\hline
\end{tabular}

(Trich nguồn: World Economic Forum Handbook on the Forth Industrial Revolution and World Economic Forum Global Risk Report 2017).

Bài viết này phân tích kinh nghiệm của Hàn Quốc, Malaysia về các giải pháp tầm chính sách nâng cao năng lực đổi mớitrong doanh nghiệp, từ đó đưa ra các gợi ý chính sách cho Việt Nam góp phần cải thiện yếu tố công nghệ và đổi mới trên đây.

\section{Chính sách nâng cao năng lực đổi mới trong doanh nghiệp ở Hàn Quốc}

Lộ trình phát triển năng lực đổi mới trong doanh nghiệp của Chính phủ Hàn Quốc được thiết kế để tạo ra môi trường nơi tất cả các doanh nghiệp bao gồm các doanh nghiệp nhỏ và doanh nghiệp siêu nhỏ có thể phát triển thành các doanh nghiệp đổi mới sáng tạo, như Hình 1. Chính phủ thường xuyên điều chỉnh các chính sách đối với doanh nghiệp để đáp ứng mục tiêu theo nhu cầu và phù hợp với đặc điểm riêng. Trong giai đoạn đầu, các chính sách tập trung hỗ trợ doanh nghiệp gián tiếp như thiết lập cơ sở hạ tầng, cung cấp dịch vự và thông tin, tiếp đến có những chính sách hồ trợ doanh nghiệp trực tiếp. Mục tiêu của Chính phủ Hàn Quốc nhằm đặt nền móng vững chắc cho các doanh nghiệp có thể phát triển thành các doanh nghiệp đổi mới sáng tạo. Chính phủ thực thi các chính sách hỗ trợ phát triển công nghệ trong doanh nghiệp tập trung theo hướng: Thư nhất, bồi dưỡng các doanh nghiệp có tiềm năng thực hiện đổi mới, định hướng các doanh nghiệp này dẫn đầu về đổi mới công nghệ. Thư hai, củng cố mạng lưới hoạt động đổi mới dựa vào ba trụ cột chính gồm khối ngành công nghiệp, khối đào tạo và khối các viện nghiên cứu làm nền tảng. Thứ $b a$, thúc đẩy phát triển thương mại hóa công nghệ làm động lực. Thư tur, khuyến khích các tổ chức công lập sử dụng ngân sách dành cho phát triển công nghệ của họ cho các doanh nghiệp hoặc mua lại công nghệ do doanh nghiệp phát triển.

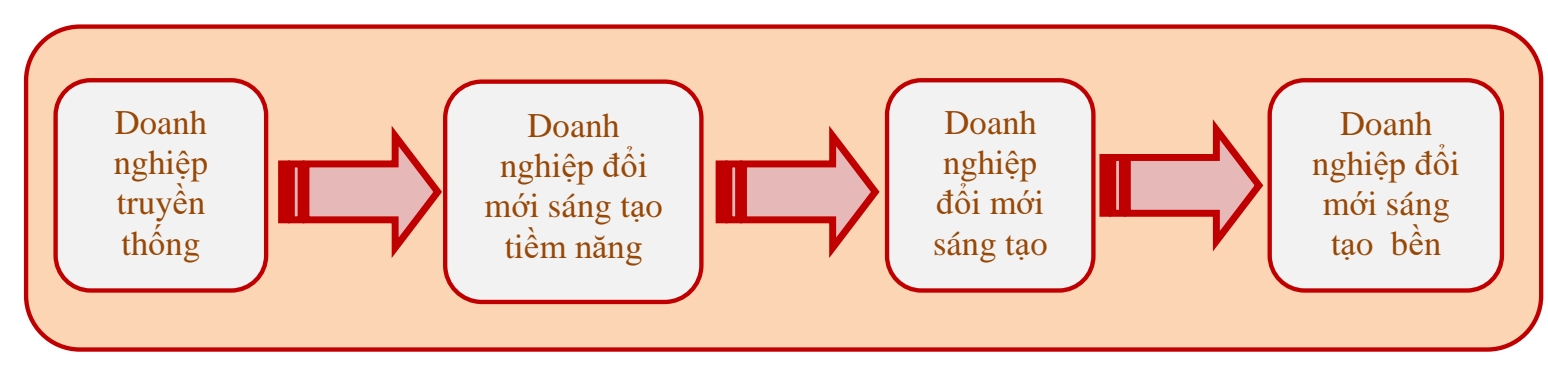

Hình 1. Giản đồ phát triển đổi mới trong doanh nghiệp tại Hàn Quốc

(Nguồn: SMBA, 2006) 
Như trình bày trong Hình 2 , Chính phủ Hàn Quốc có chính sách nhằm tăng cường năng lực đổi mới trong các doanh nghiệp được xác định cụ thể là đầu tư cho $R \& D$ trong doanh nghiệp cho phép tạo sản phẩm mới, quy trình mới có khả năng thương mại hóa các kết quả R\&D. Theo ước tính Hàn Quốc có khoảng 30.000 doanh nghiệp được hỗ trợ, tức là khoảng $10 \%$ với tổng số 330.000 doanh nghiệp sản xuất tại Hàn Quốc lúc bấy giờ năm 2006 [2].

Tập trung thúc đẩy năng lực đổi mới sáng tạo trong doanh nghiệp

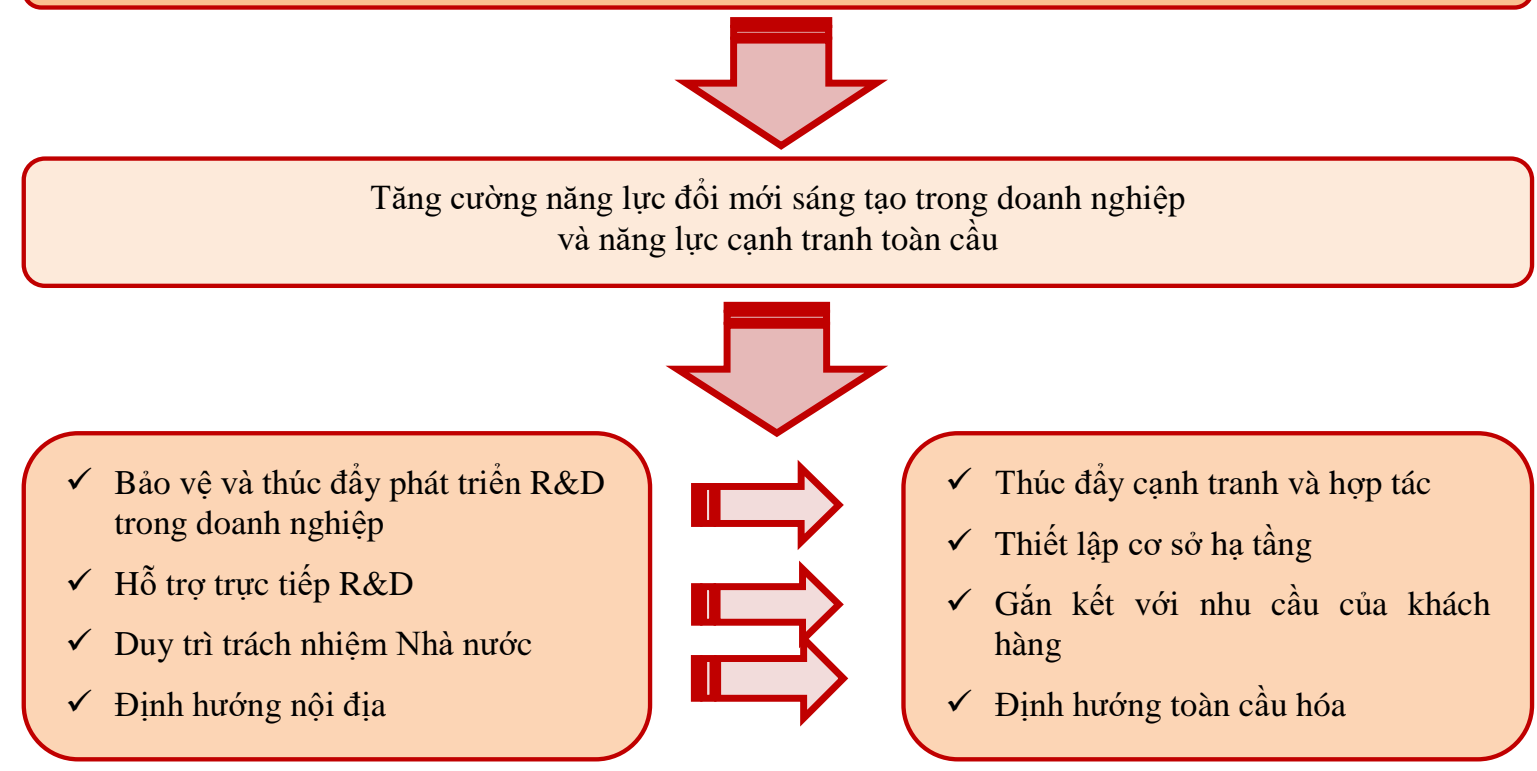

Hình 2. Hướng chính sách đổi mới hỗ trợ doanh nghiệp Hàn Quốc.

(Nguồn: Innovative SEM Advisory Committee, 2006)

Dưới đây, chúng tôi đi sâu phân tích các chính sách thúc đẩy năng lực đổi mới trong doanh nghiệp tại Hàn Quốc trong giai đoạn 1995 - 2005. Đây là giai đoạn Hàn Quốc có phát triển vượt bậc làm tiền đề để trở thành quốc gia có nền công nghiệp phát triển. Cụ thể các chính sách như sau:

\section{1/ Chinh sách hỗ trợ phát triển công nghệ}

Phương thức nâng cao năng lực đổi mới công nghệ trong doanh nghiệp tại Hàn Quốc được thực hiện thông qua các chương trình như: Chuoong trình "Đổi mói công nghệ trong doanh nghiệp". Chương trình này đã thúc đẩy đổi mới công nghệ của các doanh nghiệp, đồng thời các doanh nghiệp kế thừa các thành quả từ hoạt động $R \& D$, để tích lũy khả năng hoạt động $\mathrm{R} \& \mathrm{D}$ và tăng cường khả năng cạnh tranh công nghệ bằng cách hỗ trợ phát triển các sản phẩm mới, khuyến kích sử dụng các quy trình mới trong sản xuất; Chương trình "Đặt mua công nghệ mới" nhằm hỗ trợ thương mại hóa các công nghệ mới được phát triển tại các doanh nghiệp đổi mới bằng cách các cơ quan thuộc Chính phủ, các tổng công ty nhà nước ở các ngành (điện lực, khí, đường sắt) và các doanh nghiệp tư nhân lớn ủy quyền cho các doanh nghiệp nhỏ nghiên cứu phát triển các công nghệ mới với cam kết mua lại các sản phẩm công nghệ mới. Chương trình "Nghiên cưu đổi mới trong doanh nghiệp nhỏ của Hàn Quốc (Korean Small Business Innovation Research, KOSBIR) từ năm 1998. Trong KOSBIR có 16 cơ quan bao gồm 10 cơ quan thuộc Chính phủ và 6 cơ quan trung ương được cấp ngân sách R\&D lớn 
trên $5 \%$ tổng ngân sách cho $R \& D$ của cả nước. Nguồn ngân sách này tiếp tục được phân bổ hết cho các doanh nghiệp vừa và nhỏ trong các ngành, lĩnh vực từ đó khuyến khích đổi mới trong doanh nghiệp.

2/ Chinh sách tài chính hỗ trợ phát triển doanh nghiệp thực hiện đổi mói sáng tạo

Chính phủ cung cấp hỗ trợ tài chính trực tiếp và gián tiếp cho các doanh nghiệp đảm bảo rằng các doanh nghiệp đổi mới không thất bại do những vấn đề về tài chính. Chính phủ thúc đẩy liên doanh nhằm huy động nguồn vốn trực tiếp từ thị trường, đồng thời Chính phủ bảo lãnh tín dụng cho các doanh nghiệp không đủ điều kiện vay ngân hàng do thiếu tài sản thế chấp. Để thực hiện điều này Chính phủ Hàn Quốc cho thành lập Quỹ đầu tư mạo hiểm. Chính phủ đã tạo ra khoản đầu tư mạo hiểm trị giá 500 triệu đô la từ tháng 6/2006. Ngoài ra, Chính phủ Hàn Quốc áp dụng Chương trình bảo lãnh tín dụng cho doanh nghiệp đổi mới sáng tạo, cấp Chứng nhận doanh nghiệp đổi mới với các ưu đãi đặc biệt.

\section{3/ Chính sách uoom tạo doanh nghiẹp đổi mới}

Chính phủ đã hỗ trợ một chương trình thiết lập và vận hành "Vườn ươm doanh nghiệp" (BIs) tại các trường đại học và viện nghiên cứu. Trong Chương trình này người hưởng lợi sẽ là doanh nhân của các công ty khởi nghiệp dựa trên công nghệ và những người mới bắt đầu khởi sự doanh nghiệp. Chương trình đã cung cấp cho các doanh nghiệp vừa và nhỏ không gian hoạt động từ 2 đển 3 năm trong BIs. Năm 1998, Chính phủ bắt đầu tài trợ một số chi phí để thành lập các trung tâm BIs tại các cơ sở nghiên cứu đại học, quốc gia và công lập dưới dạng cung cấp cho chi phí hoạt động của BIs. Nếu một vườn ươm đạt hiệu suất kém, nó sẽ bị loại trừ trong danh sách người thụ hưởng cho năm tài chính tiếp theo.

4/ Chính sách thay đổi cách thức quản lý điều hành thông qua đổi mới

Chính phủ Hàn Quốc tiếp tục thúc đẩy các doanh nghiệp hoạt động đổi mới bằng cách tập trung vào hỗ trợ phát triển các công nghệ ngành mà doanh nghiệp đang hoạt động. Nhờ đó, các doanh nghiệp truyền thống có thể nâng cao năng lực đổi mới bằng cách buộc phải đồi mới cách quản lý và điều hành, đặc biệt trong quản lý các lĩnh vực phi công nghệ như tổ chức điều hành sản xuất, hoạt động tiếp thị, bố trí sắp xếp nhân lực công nghệ, thành lập nhóm dự án, liên kết sản xuất với nghiên cứu. Trong chính sách đổi mới cách thức quản lý trong doanh nghiệp, Chính phủ cũng hỗ trợ phát triển dịch vụ tư vấn doanh nghiệp ở nhiều khía cạnh từ pháp lý đến tiêu thụ sản phẩm. Hàn Quốc xây dựng hệ thống thông tin chính sách (hệ thống SPi-1357) kết hợp cổng thông tin trực tuyến (www.spi.go.kr) và trung tâm khắc phục sự cố doanh nghiệp. Hệ thống cung cấp thông tin chính sách nhanh trong 9 lĩnh vực liên quan đến tài chính, nhân lực và công nghệ bằng cách tích hợp thông tin từ các tổ chức hỗ trợ doanh nghiệp.

5/ Chính sách phát triển thị truờng công nghệ

Chính phủ yêu cầu các tổ chức công lập mua công nghệ của các doanh nghiệp đổi mới đã phát triển thành công, đồng thời các sản phẩm KH\&CN do Chính phủ phê duyệt để thực hiện. Bằng cách đó thúc đẩy phát triển công nghệ trong các doanh nghiệp và mua công khai các sản phẩm KH\&CN của doanh nghiệp. Vào tháng 7 năm 2005, Chính phủ đã giới thiệu một hệ thống hoạt động công nhận và bảo hiểm các sản phẩm công nghệ do các doanh nghiệp phát triển. Tỷ lệ đã mua sản phẩm công nghệ do doanh nghiệp vừa và nhỏ tạo ra ở mức $5 \%$ trong năm 2006, tăng lên 10\% trong năm 2010 . Số tiền mua đã tăng 400 tỷ won năm 2003 lên tới 1,1 nghìn tỷ won năm 2006 [3].

6/ Chính sách phát triển nguồn nhân lực $R \& D$ trong doanh nghiẹp

Thông qua việc thúc đẩy dự án tuyển dụng nhân lực R\&D của doanh nghiệp, Chính phủ hỗ trợ hợp tác giữa các trường đại học và phòng công nghiệp; giữa viện nghiên cứu gắn liền với doanh nghiệp để cho phép các doanh nghiệp vừa và nhỏ sử dụng nguồn nhân lực dồi dào và tài nguyên $R \& D$ từ trường đại học. Năm 2005,164 văn phòng hợp tác giữa các trường 
đại học và công nghiệp đã được thành lập và 44 văn phòng cộng tác giữa trường đại học, viện nghiên cứu với doanh nghiệp được thành lập. Đặc biệt, chương trình lựa chọn các kỹ thuật viên được đi đào tạo để giải quyết các vấn đề thiếu hụt lao động kỹ thuật trong doanh nghiệp.

\section{Chính sách nâng cao năng lực đổi mới trong doanh nghiệp ở Malaysia}

Cùng thời kỳ đổi mới ở Việt Nam năm 1986, Chính phủ Malaysia đã xác định công nghệ là một trong những nhân tố quan trọng để phát triển kinh tế. Đến năm 1991, hoạt động thương mại hóa các kết quả nghiên cứu của Malaysia mới bắt đầu xuất hiện trong Kế hoạch phát triển lần thứ 6, giai đoạn 1991-1995, nhấn mạnh vào các chương trình nghiên cứu phát triển công nghệ định hướng thị trường và tạo ra các sản phẩm có thể thương mại hóa thông qua doanh nghiệp. Các kế hoạch lần thứ 7 giai đoạn 1995-1999; lần thứ 8 giai đoạn 2000-2005; lần thứ 9 giai đoạn 2006-2010 của Malaysia tiếp tục đưa ra các biện pháp nhằm thúc đẩy hoạt động thương mại hóa kết quả nghiên cứu trong các cơ sở nghiên cứu cũng như tại các doanh nghiệp ở Malaysia. Thực tế trong giai đoạn 1995 đến 2005, Malaysia đứng trước nhiều khó khăn và rào cản trong thực thi chính sách nâng cao năng lực đổi mới trong doanh nghiệp, được tổng kết trong Hình 3 dưới đây.

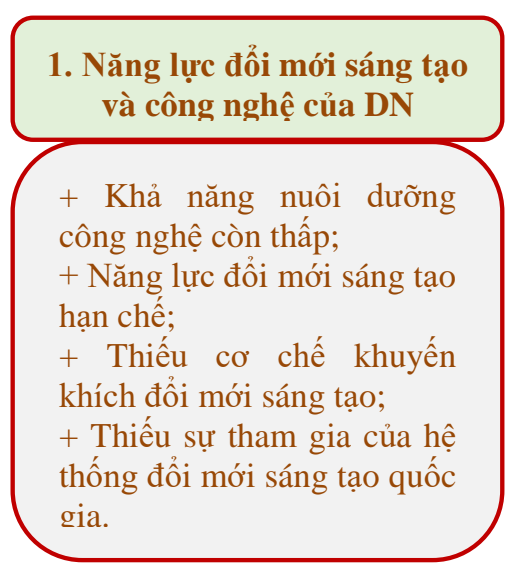

4. Thị trường công nghệ phục vụ DN

+ Thiếu thông tin về thị trường (bao gồm xuất khẩu) và đối thủ cạnh tranh;

+ Thiếu năng lực đánh giá;

+ Sự tham gia không đầy đủ

vào các mạng sản xuất.
2. Năng lực con người trong DN

+ Thiếu kỹ năng và không phù hợp với công nghệ mới;

+ Phụ thuộc vào lao động nước ngoài thiếu kỹ năng và tay nghề;

+ Hạn chế trong thu hút tài năng nước ngoài vào sản xuất kinh doanh.

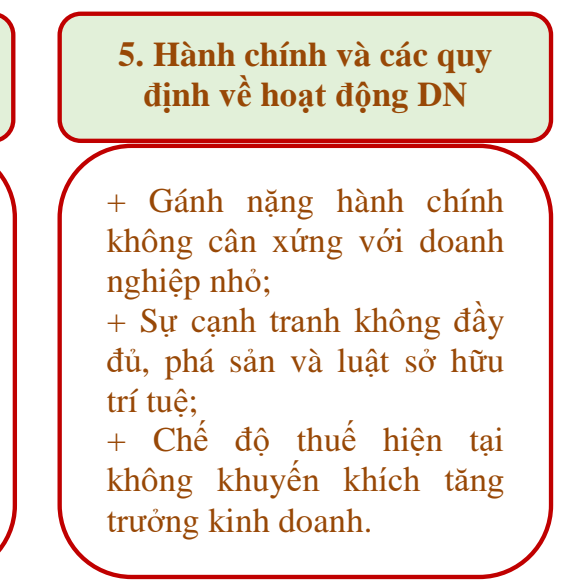

3. Nguồn tài chính phục vụ DN

+ Tín dụng dành cho doanh nghiệp thấp, chưa an toàn;

+ Phạm vi, quy mô tiếp cận nhỏ;

+ Doanh nghiệp vay vốn ngoài ngân hàng;

+ Bất đối xứng thông tin

6. Cơ sở hạ tầng và an ninh cho DN

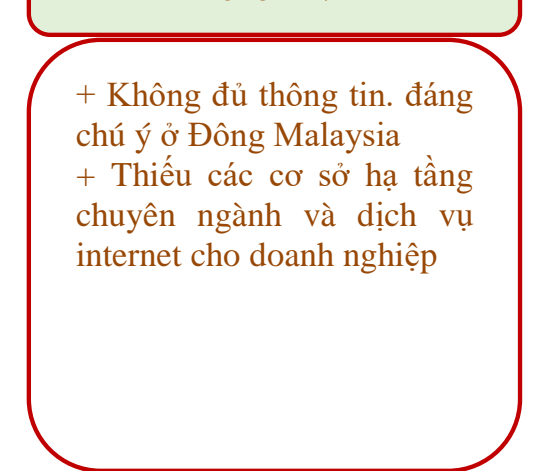

Hình 3. Những rào cản trong chính sách nâng cao năng lực đổi mới trong doanh nghiệp giai đoạn 1995-2005 của Malaysia. 
Trước tình thế khó khăn với những rào cản xã hội đặt ra lúc bấy giờ, Chính phủ Malaysia đã nỗ lực cải cách không ngừng thúc đẩy hoạt động thương mại hóa kết quả nghiên cứu của Malaysia ngày càng phát triển, đưa Malaysia trở thành quốc gia đạt được thành công trong thương mại hóa kết quả nghiên cứu hàng đầu trong khu vực Đông Nam Ả. Có thể nói Chính phủ Malaysia đã có những giải pháp chính sách hay nhằm tăng cường năng lực đồi mới trong doanh nghiệp phù hợp với điều kiện và hoàn cảnh đất nước lúc bấy giờ.

1/ Chính sách phát triển $R \& D$ trong doanh nghiệp ở Malaysia.

Malaysia là quốc gia có tiềm năng nghiên cứu khoa học và phát triển công nghệ hàng đầu trong khu vực Đông Nam Á. Theo số liệu thống kê của Văn phòng Sáng chế và Nhãn hiệu Hoa Kỳ (USPTO), trong giai đoạn 2006-2010, Malaysia là nước đứng thứ hai chỉ sau Singapore ở Đông Nam Á về số lượng bằng sáng chế (xem Bảng 2).

Bảng 2. So sánh số lượng văn bằng sở hữu trí tuệ được cấp trong giai đoạn 2006-2010 của các nước ở Đông Nam Á

\begin{tabular}{llll}
\hline Hạng & Nước & $\begin{array}{l}\text { Dân số } \\
\text { (triệu } \\
\text { người) }\end{array}$ & $\begin{array}{l}\text { Số bằng } \\
\text { sáng chế } \\
\text { 2006-2010 }\end{array}$ \\
\hline 1 & Singapore & 4,8 & 2496 \\
2 & Malaysia & 27,9 & 877 \\
3 & Thái Lan & 68,1 & 206 \\
4 & Philippines & 93,6 & 143 \\
5 & Indonesia & 232 & 74 \\
6 & Việt Nam & 83,31 & 5 \\
\hline
\end{tabular}

(Dân số: nguồn BBC năm 2011, số bằng sáng chế: nguồn USPTO)

Số liệu tại Bảng 2 cho thấy khả năng nghiên cứu sáng tạo ra các tài sản trí tuệ của Malaysia là khá cao. Đây chính là tiền đề để hoạt động thương mại hóa dưới hình thức chuyển giao (lixăng công nghệ) hay thành lập các doanh nghiệp công nghệ có điều kiện phát triển. Các doanh nghiệp Malaysia nhận được các khoản hỗ trợ cụ thể để triển khai ứng dụng, hoàn thiện và sáng tạo các công nghệ mới. Với chính sách hỗ trợ phát triển R\&D trong doanh nghiệp như hỗ trợ tài chính trực tiếp cho nhóm nghiên cứu của doanh nghiệp hoàn thiện công nghệ, khuyến khích các nhà khoa học tham gia nghiên cứu cùng doanh nghiệp, sử dụng miễn phí các phòng thí nghiệm quốc gia, tài trợ doanh nghiệp tham gia các triển lãm giới thiệu công nghệ ở nước ngoài,.... của chính phủ Malaysia đã thúc đẩy một lực lượng lớn các nhà khoa học trở lên nhanh nhạy hơn với các ứng dụng công nghệ mới vào sản xuất hàng hóa trong doanh nghiệp.

2/ Chính sách tăng cuờng năng lục đổi mới trong doanh nghiẹp

Bên cạnh việc tăng đầu tư cho nghiên cứu phát triển và thương mại hóa, năm 2010 chính phủ Malaysia đầu tư 60 tỷ đô la Mỹ dưới dạng các chương trình, các quỹ hỗ trợ thương mại hóa các kết quả nghiên cứu từ các viện nghiên cứu, các trường đại học khối kỹ thuật. Các kế hoạch tài trợ nghiên cứu phát triển công nghê mới được xây dựng và thực hiện cùng với các kế hoạch tài trợ cho nghiên cứu cơ bản truyền thống. Chẳng hạn như kế hoạch tài trợ cho nghiên cứu khám phá (ERGS), kế hoạch tài trợ nghiên cứu dài hạn (LRGS) hay kế hoạch tài trợ nghiên cứu đánh giá (PRGS). Ngoài ra, các chương trình tài trợ cũng được đa dạng hóa và mang tính chuyên biệt cho hoạt động thương mại hóa [4].

Dưới đây là các loại hình chương trình, quỹ thúc đẩy các hoạt động thương mại hóa kết quả nghiên cứu khoa học và phát triển công nghệ tập trung vào các doanh nghiệp có hoạt động đồi mới tại Malaysia. Chuoong trình đầu tu Cradle: Cấp vốn ban đầu cho việc cải tiến các công nghệ thành các sản phẩm có khả năng thương mại hóa. Chương trình cũng bao gồm cả các chương trình trợ giúp cho các doanh nghiệp công nghệ và việc bán quyền sở hữu trí tuệ của các trường đại học khối kỹ thuật. Chuoong trình hỗ trợ úng dụng tin học (DAGS): là chương trình được quản lý bởi Bộ Khoa học Công nghệ và Đổi mới Malaysia (MOSTI) cấp vốn tài trợ cho các dự án sản xuất thử nghiệm ứng dụng công nghệ thông tin truyền thông cho cộng đồng. Quỹ eContent: tài trợ cho các dự án tạo ra 
các nội dung số. Quỹ InnoFund: Được quản lý bởi MOSTI, chuyên cấp vốn cho các dự án thương mại hóa cải tiến (innovation). Chương trình tài trợ sở hưu trí tuệ và hành lang truyền thông đa phuoong tiện: Được quản lý bởi Tập đoàn phát triển truyền thông đa phương tiện, Chương trình này cung cấp hỗ trợ lên đến $70 \%$ chi phí bảo vệ quyền sở hữu trí tuệ. Tuy nhiên, điều này được thực hiện trên cơ sở hoàn trả và ứng dụng phải được thực hiện sau khi quá trình kết thúc. Chuoơng trình tài trợ nghiên cúu phát triển (MSC): Chương trình được quản lý bởi
Tập đoàn phát triển truyền thông đa phương tiện, cung cấp hỗ trợ cho hoạt động nghiên cứu và phát triển ở Malaysia. Quỹ eScience: Quản lý bởi MOSTI, tài trợ cho các dự án nghiên cứu phát triển trong các lĩnh vực ưu tiên ở các trường đại học. Quỹ công nghệ (Techno Fund): tài trợ cho các dự án tiền thương mại hóa và các dự án có khả năng tạo ra quyền sở hữu trí tuệ. Chuoong trình tài trợ uoom mầm cho doanh nghiẹp công nghệ thành lập quỹ tài trợ cho việc sáng tạo để tạo ra các công ty mới về công nghệ [5].

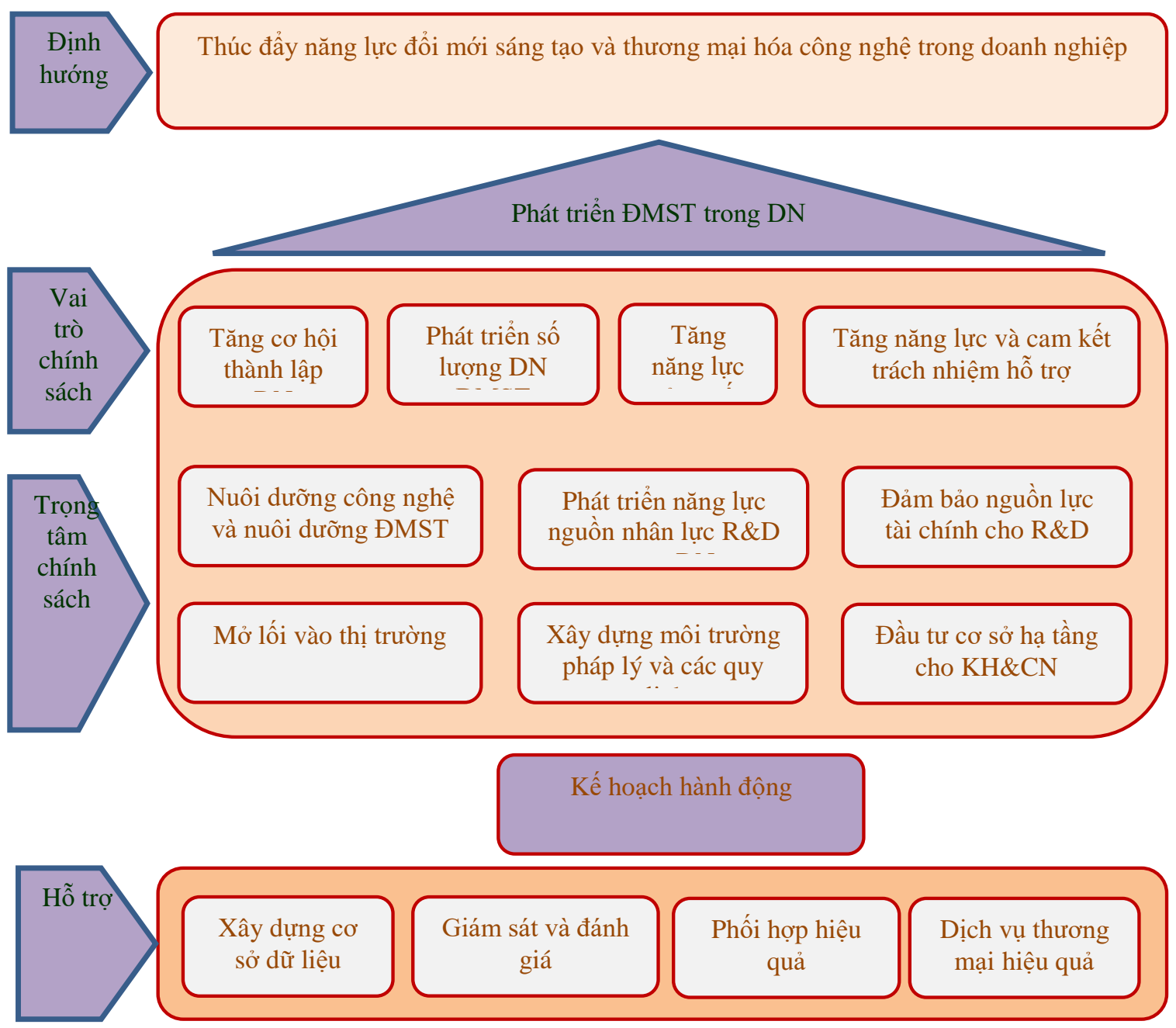

Hình 4. Chính sách nâng cao năng lực đổi mới và thương mại hóa coog nghệ trong doanh nghiệp của Malaysia. 
Về mặt tổ chức đối với sự phát triển hoạt động thương mại hóa, Malaysia thực hiện: i) khuyến khích thành lập các trường đại học tư nhân, ưu tiên hoạt động trong lĩnh vực công nghệ, ii) khuyến khích thành lập các trung tâm tư vấn công nghệ và dịch vụ, iii) nhấn mạnh vào nghiên cứu, chẳng hạn như đưa ra các chương trình nghiên cứu, thiết lập khái niệm "đại học nghiên cứu" và "đại học đỉnh cao" cho các trường đại học công, khuyến khích thành lập các trung tâm quản lý nghiên cứu trong các cơ sở nghiên cứu và doanh nghiệp và cuối cùng là iv) nhấn mạnh vào thương mại hóa các nghiên cứu triển khai. Bên cạnh các chính sách về khoa học công nghệ và tổ chức, Malaysia cung đã đưa ra nhiều chính sách về thuế để khuyến khích việc thành lập các doanh nghiệp công nghệ mới từ các nghiên cứu triển khai. Các chính sách ưu đãi về tài chính bao gồm miễn thuế thu nhập cho các doanh nghiệp công nghệ hiện đại, chi trả $100 \%$ chi phí nâng cấp phát triển công ty, miễn thuế nhập khẩu, cấp vốn xây dựng cơ sở hạ tầng và một số ưu đãi khác.

Những cải cách về chính sách của chính phủ Malaysia đối với hoạt động thương mại hóa kết quả nghiên cứu không chỉ đối với doanh nghiệp sản xuất mà còn các trường đại học khối kỹ thuật, thậm chí thúc đẩy từng tổ chức, từng cá nhân hoạt động $R \& D$ quan tâm phát triển hoạt động này.

Tóm lại, nghiên cứu này đã xem xét ngắn gọn tổng thể các chính sách nâng cao năng lực đổi mới trong doanh nghiệp tại Hàn Quốc, Malaysia, cụ thể bao gồm các chính sách chính về phát triển công nghệ, hỗ trợ tài chính, vườn ươm doanh nghiệp đổi mới sáng tạo, đổi mới cách thức quản lý, phát triển thị trường công nghệ và đào tạo, phát triển nguồn nhân lực KH\&CN trong doanh nghiệp. Bên cạnh đó còn có chính sách hợp tác công - tư trong việc thúc đẩy năng lực đổi mới trong doanh nghiệp.

\section{Một số gợi ý chính sách cho Việt Nam trong hoạch định chính sách nâng cao năng lực đổi mới của doanh nghiệp}

\subsection{Bài học kinh nghiệm}

Các quốc gia Hàn Quốc, Malaysia đều có một hệ thống chính sách đa dạng nâng cao năng lực đổi mới của doanh nghiệp. Tiêu biểu là những chính sách hỗ trợ phát triển công nghệ; đổi mới công nghệ trong doanh nghiệp; ướm tạo doanh nghiệp dựa trên công nghệ mới; thực hiện đổi mới sáng tạo; thay đổi cách thức quản lý điều hành tạo môi trường thuận lợi nhất cho thực hiện đổi mới sáng tạo; các giải pháp hỗ trợ trực tiếp cho những ứng dụng các công nghệ mới vào sản xuất; ... Đặc biệt trong giai đoạn chuyển đổi từ mô hình doanh nghiệp truyền thống sang mô hình doanh nghiệp đổi mới linh hoạt dựa trên công nghệ, nổi bật nhất vẫn là những chính sách hỗ trợ tài chính cho $R \& D$ và cơ chế đặc thù theo mô hình quỹ đã đề cập ở trên. Như vậy, nước ta có thể xem xét, cải tiến và áp dụng với từng chính sách cụ thể trong giai đoạn chuyển đổi hiện nay.

Bên cạnh đó, các quốc gia này đã thực hiện từng bước chiến lược nâng cao năng lực sáng tạo và cơ chế hỗ trợ tích cực các hoạt động R\&D trong doanh nghiệp gắn chặt với thương mại hóa, thậm chí như Hàn Quốc các cơ quan, tổ chức thuộc bộ máy nhà nước đứng ra mua lại các sáng chế, các công nghệ sản xuất triển vọng của doanh nghiệp để rồi đầu tư trở lại mở rộng sản xuất dựa trên các công nghệ đó. Ngoài ra còn rất nhiều kinh nghiệm quý khác cần học hỏi.

\subsection{Một số gợi suy trong hoạch định chính sách đối với Việt Nam}

Từ kinh nghiệm của Hàn Quốc, Malaysia ở hai thập niên cuối của thế kỷ 20 và thập niên đầu của thế kỷ 21 khi mà điều kiện phát triển khá tương đồng với điều kiện Việt Nam hiện nay dẫn tới một số gợi ý chính sách đổi mới sau. 


\section{Thư nhất, thiết lập hệ thống ghi nhận công nghệ mới trong doanh nghiệp.}

Để bảo đảm việc hỗ trợ tài chính cho đầu tư R\&D trong doanh nghiệp được chính xác, Chính phủ cần giao cho một cơ quan chuyên trách xây dựng hệ thống ghi nhận công nghệ mới từ các tổ chức $R \& D$, các doanh nghiệp có R\&D tại Việt Nam. Hệ thống này sẽ là cơ sở khoa học cho việc thẩm định để hỗ trợ kinh phí cho những sản phẩm công nghệ mới đang trong giai đoạn tiếp cận thị trường. Bất kỳ công nghệ mới nào đạt tiêu chuẩn do cơ quan quản lý nhà nước quy định thì đơn vị chủ trì sẽ được hỗ trợ dưới dạng quyền ưu tiên bao gồm quyền ưu tiên đăng ký kinh phí từ quỹ hỗ trợ phát triển của Chính phủ và các quỹ phát triển công nghệ của các ngân hàng thương mại; quyền ưu tiên quảng bá tại những chiến dịch truyền thông hội chợ triển lãm công nghệ. Quỹ Phát triển KH\&CN Quốc gia, Quỹ Đổi mới công nghệ Quốc gia có thể tài trợ kinh phí để hoàn thiện công nghệ mới do các đơn vị chủ trì nghiên cứu đề xuất.

Xây dựng và khai thác chủ động cơ sở dữ liệu quốc gia về công nghệ trong doanh nghiệp sẽ giúp cải thiện các định hướng kinh doanh, định hướng thị trường tiêu thụ sản phẩm, kết hợp với thể chế chính sách để trở lại đổi mới sản xuất, chủ động định hướng triển khai phát triển công nghệ trên khắp các hệ thống đào tạo nghề và phân bổ nguồn nhân lực có trình độ phục vụ sản xuất, tăng cường các hướng nghiên cứu triển khai công nghệ nguồn, đẩy nhanh ứng dụng thành tựu khoa học công nghệ vào trong các ngành công nghiệp sản xuất đang còn hạn chế về trình độ công nghệ, nâng cao chủ động khả năng sáng tạo và liên kết giữa các ngành, lĩnh vực trọng điểm.

Thư hai, cấp bảo lãnh cho các khoản vay phuc vu R\&D trong doanh nghiệp

Ở Việt Nam, việc vay vốn từ các tổ chức tài chính, đặc biệt là các ngân hàng thương mại là không dễ dàng đối với các doanh nghiệp nhỏ và vừa, nhất là các doanh nghiệp $\mathrm{KH \& CN}$, vì các khoản vay này luôn bị các ngân hàng coi là có tính rủi ro cao, do các doanh nghiệp nhỏ và vừa gặp nhiều bất trắc và dễ tổn thương trước các biến động từ thị trường và nền kinh tế. Vì vậy, để hỗ trợ các doanh nghiệp nhỏ vay vốn đầu tư cải tiến công nghệ, các quỹ đổi mới công nghệ quốc gia cần đưa vào vận hành cơ chế cấp bảo lãnh cho các khoản vay phục vụ R\&D. Cơ chế này cần có một quy trình xét duyệt bảo lãnh đòi hỏi linh hoạt, nhưng không được thiếu tính chính xác, chặt chẽ và được kiểm toán đầy đủ. Nếu không thì việc duyệt bảo lãnh biến thành cơ chế xin - cho tùy hứng, tạo cơ hội cho tham nhũng phát sinh. Ngược lại, nếu cơ quan duyệt bảo lãnh vì sợ trách nhiệm mà làm việc quá chặt tay, thì các dự án đầu tư $R \& D$ - dù có triển vọng tốt nhưng trong bản chất tự thân đã có tính mạo hiểm - sẽ không được bảo lãnh, và không huy động được nguồn vốn cần thiết.

Do vậy, Quỹ Phát triển KH\&CN Quốc gia hoặc Quỹ Đồi mới công nghệ Quốc gia cần cung cấp dịch vụ bảo lãnh tín dụng công nghệ. Hiện nay, Quỹ Đổi mới công nghệ Quốc gia là phù hợp nhất. Khoản bảo lãnh này có nhiều hình thức, nhưng mục tiêu chung là đảm bảo các tổ chức cho vay thu hồi khoản nợ trong trường hợp người đi vay mất khả năng thanh toán. Nhờ vậy khuyến khích các tổ chức tài chính cho vay đối với các doanh nghiệp nhỏ và vừa có dự án triển vọng tốt nhưng không có đủ tài sản thế chấp, hoặc không có hồ sơ tín dụng đầy đặn phù hợp để chứng minh uy tín trả nợ.

Thư ba, tăng cuờng năng lục nghiên cưu, triển khai các công nghệ mới tại nhũng doanh nghiệp sản xuất

Củng cố nhận thức về vai trò then chốt của đổi mới dựa trên công nghệ trong doanh nghiệp; hỗ trợ doanh nghiệp nâng cao năng lực đổi mới công nghệ; xây dựng mô hình doanh nghiệp công nghệ; thu hút các tổ chức khoa học và cá nhân tham gia vào các chương trình, mục tiêu khoa học và công nghệ quốc gia hướng tới phục vụ doanh nghiệp sản xuất. Hoạch định chính sách tạo hướng đi cho tương lai với nòng cốt là những doanh nghiệp hàng đầu về công nghệ, đặc biệt là những công nghệ của Cách mạng công nghiệp lần thứ tư; khuyến khích tạo cơ chế cho doanh nghiệp thường xuyên nhập khẩu các bí quyết công nghệ để ứng dụng, 
nghiên cứu phát triển tiếp nhằm phục vụ đổi mới sản xuất; tập trung thực hiện một đến hai dự án trọng điểm khoa học và công nghệ quốc gia gắn chặt với ngành, lĩnh vực sản xuất thế mạnh quốc gia; tập trung nghiên cứu phát triển một số ít công nghệ nguồn quan trọng trong kế hoạch khoa học và công nghệ quốc gia gắn với ứng dụng trong các doanh nghiệp lớn thuộc các ngành, lĩnh vực sản xuất chủ lực quốc gia;...

Trong chính sách cần đặt vai trò hàng đầu là các trường đại học khối kỹ thuật, cũng như vai trò then chốt của các công nghệ chủ đạo trong các doanh nghiệp thuộc khối ngành công nghiệp sản xuất và dịch vụ.

Thư tư, tăng cường gắn kết giữa khối doanh nghiệp sản xuất với khối nghiên cứu thông qua các hoạt động khoa học công nghệ cu thể

Khuyến khích và tạo điều kiện cho các hoạt động triển lãm, trưng bày, giới thiệu thành tựu sáng tạo trong các lĩnh vực quan trọng của sản xuất truyền thống (dệt may, da giày, cơ khí,...), các ngành công nghiệp chiến lược mới nồi (thông tin viễn thông, di động, điện tử,...), dịch vụ hiện đại (thương mại điện tử, thanh toán, giao dịch điện tử,...), để thúc đẩy hợp tác phát triển công nghệ tiên tiến ứng dụng các công nghệ xanh, thông minh. Trong quá trình hợp tác, tăng cường nghiên cứu phổ biến và phát triển công nghệ cao, nắm bắt thông tin khoa học và công nghệ mới, bí quyết công nghệ và hệ thống thiết kế tổng thể; phát triển công nghệ phổ biến trên một số lĩnh vực sản xuất chính để có sở hữu trí tuệ độc lập; xây dựng và hoàn thiện chính sách hỗ trợ sáng tạo dựa trên thành quả từ hoạt động khoa học công nghệ. Trao đổi kinh nghiệm giữa các chuyên gia, doanh nghiệp công nghệ, khuyến khích các doanh nghiệp sản xuất thành lập trung tâm nghiên cứu thiết kế và xuất khẩu các sản phẩm thương hiệu riêng của mình trong quá trình chuyển đổi mô hình sản xuất nhanh như hiện nay. Phát triển toàn diện đào tạo gắn với nghiên cứu sáng tạo, thành lập các giải thưởng sáng tạo công nghiệp quốc gia, các sáng tạo của toàn xã hội để kích thích sự nhiệt tình và tính chủ động. Thành lập một số liên minh đổi mới công nghệ theo ngành nghề, lĩnh vực sản xuất; thực hiện các hợp tác nghiên cứu theo hướng đổi mới nâng cao năng lực công nghệ trong doanh nghiệp, nắm bắt một số cơ hội tác động toàn cầu về năng lực cạnh tranh công nghiệp dựa trên công nghệ để tăng cường mạnh mẽ hoạt động đổi mới hướng tới nền sản xuất của tương lai.

\section{Tài liệu tham khảo}

[1] World Economic Forum (2018). Readiness for the future of Production report 2018.

[2] Nayanee Gupta, David W. Healey, Aliza M. Stein (2013), Innovation Policies of South Korea, Institute for Defense Analyses. IDA document D4984.

[3] Joo-Yong Kim (2008) SME Innovation Policies in Korea, the APEC SME innovation Center in TIPA, Korea.

[4] Malaysian Institute of Economic Research (2004): Macro Framework Section of the 3rd Industrial Master Plan Study (2006-2020), Malaysian Ministry of International Trade.

[5] Planning Unit (2001), Eighth Malaysia Plan (2001-2005): Percetakan Nasional Malaysia Berhad, Kuala Lumpur Branch. 


\title{
Enhance the Capacity of Innovation in the Enterprises from Experience of South Korea, Malaysia and Propose to Vietnam
}

\author{
Vu Van Khiem, Ho Nam Nam Phuong, Bui Tien Dung \\ Van Lang University, 45 Nguyen Khac Nhu, Co Giang, District 1, Ho Chi Minh City \\ University of Social Sciences and Humanities, Hanoi National University, \\ 336 Nguyen Trai, Thanh Xuan, Hanoi \\ Institute of Science, Technology and Innovation, Ministry of Science and Technology, \\ 38 Ngo Quyen, Hoan Kiem, Hanoi
}

\begin{abstract}
This article explores the policy of enhancing the ability of innovation in the business with the experience of Korea, Malaysia. These are the two countries that are implementing the policy of enhancing the capacity for innovation in successful businesses. These countries have a different starting point, but they have implemented innovative innovation policies in their respective businesses that have enabled them to quickly become states achieved high rank in the world. South Korea and Malaysia have many similarities with Vietnam today provokes our country into making policies to enhance the innovation capacity of enterprises.
\end{abstract}

Keywords: Policy, capacity for innovation, enterprise. 